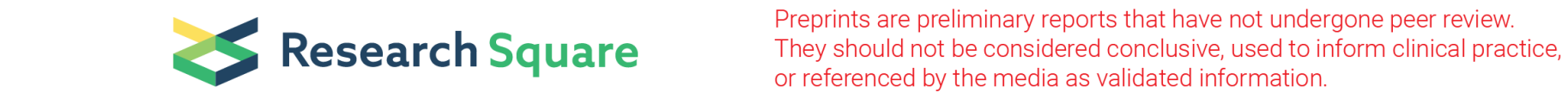

\title{
Unmet Needs and Quality of Life of Caregivers of Korean Breast Cancer Survivors: A Cross-Sectional Study
}

\author{
Jong Won Lee \\ University of Ulsan College of Medicine \\ Jihyoun Lee \\ Soonchunhyang University College of Medicine \\ Min Hyuk Lee \\ Soonchunhyang University College of Medicine \\ Se Kyung Lee \\ Sungkyunkwan University School of Medicine \\ Wan Sung Kim \\ Hanyang University College of Medicine \\ So-Youn Jung \\ National Cancer Center \\ Zisun Kim \\ Soonchunhyang University College of Medicine \\ Juhyung Lee \\ Chonbuk National University Medical School \\ Hyun Jo Youn ( $\nabla$ yhj0903@jbnu.ac.kr) \\ परास https://orcid.org/0000-0002-2407-8537
}

\section{Research}

Keywords: Breast neoplasms, caregivers, unmet need, quality of life

Posted Date: June 10th, 2020

DOl: https://doi.org/10.21203/rs.3.rs-33805/v1

License: @ (1) This work is licensed under a Creative Commons Attribution 4.0 International License. Read Full License 


\section{Abstract}

Backgroud: As the survival rates of cancer patients have been increasing due to early diagnosis and technological advances in treatment, their caregiver burden has also emerged as an important issue. In view of this situation, this study aims to investigate the unmet needs and quality of life of caregivers of Korean breast cancer survivors.

Methods: A multicenter cross-sectional interview survey was performed among 160 caregivers of Korean breast cancer survivors. Caregivers who gave written informed consent to participate completed the Comprehensive Needs Assessment Tool for Cancer Caregivers and EuroQol-5 Dimensions. Data were analyzed using the t-test, ANOVA and multiple regression analysis.

Results: The mean age of the caregivers was 46.4 years, $44.4 \%$ (71/160) were spouses of patients, and $52.5 \%$ (84/160) were personally taking care of cancer survivors. Unmet needs were highest in the 'healthcare staff' domain (mean \pm SD: $1.69 \pm 1.11$ ), and the item with the highest level of unmet needs was 'needed information about the current status of the patient's illness and its future courses' (1.98 \pm 1.04$)$. Unmet needs were correlated with age, educational level, marital status, employment, religion and psychosocial status. Poorer quality of life was closely related to higher levels of unmet needs. In multiple regression analysis, age, employment, religion, and levels of stress and despair were closely associated with unmet needs.

\section{Introduction}

In 2018 , there were an estimated $18,078,957$ new cases of cancer diagnosed worldwide, and among them, 2,088,849 patients (11.6\%) were diagnosed with breast cancer. Thus, breast cancer was the second most common cancer occurring worldwide after lung cancer, and its incidence was highest of all types of cancers in women, accounting for $24.2 \%$ of all cancers diagnosed in women in 2018 [1]. In Korea, the incidence of breast cancer has been increasing each year, with 26,534 new cases diagnosed in 2017 , and breast cancer is the most common cancer in women (20.3\%) [2].

As early diagnosis and technological advances in treatment have led to the increase of the survival rates of cancer patients, the number of cancer survivors has been on the rise. Compared to other types of cancers, breast cancer have better prognosis, and the 5-year and 10-year relative survival rates of Korean breast cancer patients have been reported to be $93.2 \%$ and $87.7 \%$, respectively. As described above, the incidence of breast cancer has been increasing each year and the survival rates are high. Of 1,867,405 Korean cancer survivors, breast cancer survivors are reported to be 217,203 people, accounting for $11.6 \%$ [2].

As the number of cancer survivors has been growing, the roles of caregivers taking care of them have also been increasing. Caregivers are known to provide physical, emotional and practical support for cancer survivors and play an important role in treatment decision making [3, 4]. Therefore, efforts to accurately identify and address the unmet needs and related risk factors of caregivers as well as cancer survivors are a vital element in improving the quality of cancerrelated medical services and health outcomes in survivors [5].

Many caregivers have various problems, such as anxiety, depression, sleep disturbance and financial difficulties, as well as the burden of taking good care of cancer survivors [6, 7]. These problems faced by caregivers are closely related to survivors' well-being, and unmet needs of caregivers have a negative effect on survivors' health outcomes [8]. The caregiver and cancer survivor work together as a group with a shared goal, relying on each other in the fight against cancer.

Since caregivers' quality of life (QoL) has a huge impact on the treatment of cancer survivors, it is necessary to analyze their QoL to find ways to improve the efficiency of medical service [9]. Identifying unmet needs of caregivers and addressing them through appropriate interventions are essential to improving QoL of caregivers, and they ultimately allow us to provide better care for survivors [10]. Therefore, healthcare staff should make efforts to ensure effective utilization of the healthcare system by solving the problems faced by caregivers by addressing their unmet needs.

Taken together, identification of unmet needs and QoL of caregivers and analysis of related risk factors are crucial for improving treatment effects in cancer survivors. However, so far, most studies have been focused on the analysis of the unmet needs of cancer survivors from a partial perspective, overlooking or not paying enough attention to the unmet needs of caregivers, and comprehensive studies of caregivers of specific cancer types have very rarely been conducted.

Therefore, this study aimed to identify the characteristics and unmet needs of caregivers of Korean breast cancer survivors and analyze the relationships between the related factors including QoL with a view to contributing to the development and implementation of clinical interventions to address unmet needs of caregivers of Korean breast cancer survivors.

\section{Methods}

Study Participants

A cross-sectional interview survey was conducted among a total of 160 people over the period from July 2016 to August 2017. The participants were recruited among the caregivers of breast cancer survivors from 6 medical centers in Korea (Jeonbuk National University Hospital, National Cancer Center, Samsung Medical Center, Myongji Hospital, and Soonchunhyang University Seoul and Bucheon Hospitals) and they signed a written informed consent to participate in the survey after they were provided with pertinent information about the study. The survey was carried out by professional coordinators of each medical center, and this study was conducted after obtaining the approval of the institutional review board of each institution.

Measurements 
The needs of breast cancer caregivers were assessed by the Comprehensive Needs Assessment Tool for Cancer Caregivers (CNAT-C), which was developed at Korea's National Cancer Center [11]. CNAT-C is a valid and reliable measure to evaluate comprehensive needs in caregivers of Korean cancer survivors. CNAT-C consists of 41 items in seven domains: health and psychological problem (6 items), family/social support (5 items), health care staff (8 items), information and education ( 8 items), religious support ( 2 items), hospital service (6 items), and practical support (6 items) (Supplementary table 1$)$. The participants responded to each item on a 4 -point Likert scale $(0=$ no need, $1=$ low need, $2=$ moderate need, $3=$ high need $)$ based on their experience in the past one month.

Regarding stress, participants were required to select a response among "little", "a little" or "high" to answer the question 'How much stress do you feel in your daily life?' With respect to despair and thoughts of suicide, respondents answered 'yes' or 'no' in response to the questions 'Have you ever felt despair strong enough to disrupt your daily life for more than two weeks in a row in the past year?' and 'Have you ever thought about dying in the last year?', respectively.

The QoL of caregivers was measured using EuroQol-5 Dimensions (EQ-5D), which has been validated in Korean subjects, and a total of five domains of the subject's mobility, self-care, usual activities, pain/discomfort and anxiety/depression were assessed using a three-point scoring system $(1=$ no problem; 2 = some problems; 3 = severe problems) [12]. EQ-5D has been used in studies on cancer survivors [13]. In this study, analysis was conducted by dividing the respondents into two groups: caregivers who had one or more problems and those who had no problem in those areas.

The questionnaire survey also included items about the following characteristics of caregivers: age, sex, relationship with the survivor, educational level, marital status, care status, employment status, and religiousness.

Statistical Analyses

Principal component analysis was used for factor extraction, and the eigenvalue-one criterion was used. Factor analysis was conducted using the varimax method, an orthogonal rotation method. The t-test and ANOVA were used for comparative analysis of the need score for each factor and demographic and clinical characteristics of caregivers. To investigate the influence of major variables on needs, multiple regression analysis was conducted by using the need score for each factor as the dependent variable and using variables which were found to be statistically significant through univariate analysis as independent variables. All analyses were conducted using SPSS version 23.0 (SPSS Inc., Chicago, IL, USA), and a $p$ value $<0.05$ was considered as statistically significant on two-tailed analyses.

\section{Results}

\section{Participant Characteristics}

The mean age of the caregivers was 46.4 years. Among the participants, people aged under 40 years were 51 people (31.8\%), making up the highest proportion of the participants, and 55.0\% (88/160) were males. Regarding the relationship between the caregiver and breast cancer survivor, 71 people (44.4\%) were spouses of breast cancer survivors, and 40 people (25.0\%) were their children. As for marital status, 76.3\% (122/160) were married. Regarding educational level, 100 people (62.5\%) graduated from college or university, and 84 people (52.5\%) were currently personally taking care of breast cancer survivors. $69.4 \%(111 / 160)$ of the participants had a job, and $63.1 \%(101 / 160)$ had religion (Table 1$)$. 
Table 1

Participant characteristics

\begin{tabular}{|c|c|}
\hline Characteristics & Number (\%) \\
\hline \multicolumn{2}{|l|}{ Age (years) } \\
\hline$<40$ & $51(31.8)$ \\
\hline $40 \sim 49$ & $39(24.4)$ \\
\hline $50 \sim 59$ & $39(24.4)$ \\
\hline$\geq 60$ & 31 (19.4) \\
\hline \multicolumn{2}{|l|}{ Sex } \\
\hline Male & $88(55.0)$ \\
\hline Female & $72(45.0)$ \\
\hline \multicolumn{2}{|l|}{ Relationship } \\
\hline Spouse & $71(44.4)$ \\
\hline Parent & $17(10.6)$ \\
\hline Children & $40(25.0)$ \\
\hline Sibling & $23(14.4)$ \\
\hline Others & $9(5.6)$ \\
\hline \multicolumn{2}{|l|}{ Education } \\
\hline High school & 60 (37.5) \\
\hline College & $100(62.5)$ \\
\hline \multicolumn{2}{|l|}{ Marital status } \\
\hline Single & $32(20.0)$ \\
\hline Married & $122(76.3)$ \\
\hline Separated* & $6(3.7)$ \\
\hline \multicolumn{2}{|l|}{ Care } \\
\hline Yes & $84(52.5)$ \\
\hline No & $76(47.5)$ \\
\hline \multicolumn{2}{|l|}{ Employment } \\
\hline Employed & $111(69.4)$ \\
\hline Unemployed & 49 (30.6) \\
\hline \multicolumn{2}{|l|}{ Religion } \\
\hline Yes & $101(63.1)$ \\
\hline No & $59(36.9)$ \\
\hline
\end{tabular}

Factor analysis of needs

Factor analysis was carried out to investigate the needs of breast cancer caregivers. As a result, a total of 6 factors were extracted and they were named based on the contents as follows: 'healthcare staff', 'family/social support', 'practical support', 'information and education', 'psychological problem', and 'religious support' (Supplementary table 2). Among the top 10 unmet needs, 9 items were in the 'healthcare staff' domain and 1 item in the 'information and education' domain (Table 2). The highest unmet need was found in the domain of 'healthcare staff' (mean \pm SD; $1.69 \pm 1.11$ ) and the item with the highest unmet need was 'needed information about the current status of the patient's illness and its future courses' (1.98 \pm 1.04$)$. 


\begin{tabular}{|c|c|c|c|}
\hline Rank & Item & $\begin{array}{l}\text { Score } \\
\text { (Mean } \\
\pm \text { SD) }\end{array}$ & Domain \\
\hline 1 & Needed information about current status of patient's illness and its future courses & $\begin{array}{l}1.98 \pm \\
1.04\end{array}$ & $\begin{array}{l}\text { Healthcare } \\
\text { staff }\end{array}$ \\
\hline 2 & Wished nurse to promptly attend to patient's discomfort and pain & $\begin{array}{l}1.92 \pm \\
1.12\end{array}$ & $\begin{array}{l}\text { Healthcare } \\
\text { staff }\end{array}$ \\
\hline 3 & Wished doctor to be easy, specific, and honest in his/her explanation & $\begin{array}{l}1.92 \pm \\
1.14\end{array}$ & $\begin{array}{l}\text { Healthcare } \\
\text { staff }\end{array}$ \\
\hline 4 & Wished to be able to seek doctor in a quick and easy way when in need & $\begin{array}{l}1.91 \pm \\
1.16\end{array}$ & $\begin{array}{l}\text { Healthcare } \\
\text { staff }\end{array}$ \\
\hline 5 & Needed information about tests and treatments & $\begin{array}{l}1.89 \pm \\
1.10\end{array}$ & $\begin{array}{l}\text { Healthcare } \\
\text { staff }\end{array}$ \\
\hline 6 & Needed information about caring for the patient (symptom management, diet, exercise, etc.) & $\begin{array}{l}1.88 \pm \\
1.11\end{array}$ & $\begin{array}{l}\text { Information } \\
\text { and } \\
\text { education }\end{array}$ \\
\hline 7 & $\begin{array}{l}\text { Needed a designated hospital staff who would be able to provide counseling for any concerns and guidance with the } \\
\text { course of the treatment, from the point of diagnosis to the period after the discharge }\end{array}$ & $\begin{array}{l}1.74 \pm \\
1.10\end{array}$ & $\begin{array}{l}\text { Healthcare } \\
\text { staff }\end{array}$ \\
\hline 8 & Wished nurse to explain treatment or care that was being given to the patient & $\begin{array}{l}1.69 \pm \\
1.13\end{array}$ & $\begin{array}{l}\text { Healthcare } \\
\text { staff }\end{array}$ \\
\hline 9 & Wished to be respected and treated as a person by my doctor & $\begin{array}{l}1.64 \pm \\
1.10\end{array}$ & $\begin{array}{l}\text { Healthcare } \\
\text { staff }\end{array}$ \\
\hline 10 & Needed space reserved for caregivers & $\begin{array}{l}1.63 \pm \\
1.13\end{array}$ & $\begin{array}{l}\text { Healthcare } \\
\text { staff }\end{array}$ \\
\hline
\end{tabular}

Needs by sociodemographic characteristics

As age increased, the levels of unmet needs became higher, and there were statistically significant differences in the domains of family/social support, psychological problem, and religious support. In terms of educational level, the educational level of high school or lower was related to higher unmet needs in family/social support, psychological problem and religious support. As for differences in needs according to marital status, the group of separated people (divorce, separation or bereavement) reported higher unmet needs in psychological problems and religious support. Regarding employment status, the employed group showed higher unmet needs in family/social support than the unemployed group. The religious group expressed higher unmet needs in religious support compared to the irreligious group. Other differences in unmet needs according to sex, the relationship with the cancer survivor, and care status were not statistically significant (Table 3). 
Table 3

Needs by sociodemographic characteristics of participants

\begin{tabular}{|c|c|c|c|c|c|c|c|c|}
\hline Variable & $n(\%)$ & Total & $\begin{array}{l}\text { Healthcare } \\
\text { staff }\end{array}$ & $\begin{array}{l}\text { Family / Social } \\
\text { support }\end{array}$ & $\begin{array}{l}\text { Practical } \\
\text { support }\end{array}$ & $\begin{array}{l}\text { Information and } \\
\text { education }\end{array}$ & $\begin{array}{l}\text { Psychological } \\
\text { problem }\end{array}$ & $\begin{array}{l}\text { Religious } \\
\text { support }\end{array}$ \\
\hline \multicolumn{9}{|l|}{ Age (years) } \\
\hline$<40$ & 51(31.8) & $\begin{array}{l}1.02 \pm \\
0.67 a\end{array}$ & $1.61 \pm 0.96$ & $0.58 \pm 0.62 a$ & $0.79 \pm 0.75$ & $1.29 \pm 0.97 a$ & $1.06 \pm 0.90 a$ & $0.77 \pm 0.80 a$ \\
\hline $40 \sim 49$ & $39(24.4)$ & $\begin{array}{l}1.10 \pm \\
0.77 a\end{array}$ & $1.62 \pm 0.92$ & $0.80 \pm 0.85 \mathrm{ab}$ & $0.81 \pm 0.81$ & $1.35 \pm 1.03 \mathrm{ab}$ & $1.20 \pm 0.95 a$ & $\begin{array}{l}0.82 \pm \\
0.87 a b\end{array}$ \\
\hline $50 \sim 59$ & $39(24.4)$ & $\begin{array}{l}1.31 \pm \\
0.79 \mathrm{ab}\end{array}$ & $1.74 \pm 0.89$ & $1.06 \pm 0.95 b$ & $0.93 \pm 0.77$ & $1.60 \pm 1.02 \mathrm{ab}$ & $1.34 \pm 0.97 a$ & $1.19 \pm 0.88 b c$ \\
\hline$\geq 60$ & $31(19.4)$ & $\begin{array}{l}1.51 \pm \\
0.78 \mathrm{~b}\end{array}$ & $1.86 \pm 0.93$ & $1.20 \pm 0.92 b$ & $0.87 \pm 0.85$ & $1.81 \pm 0.92 b$ & $1.79 \pm 1.08 b$ & $1.53 \pm 0.95 c$ \\
\hline$p$-value & & 0.024 & 0.624 & 0.005 & 0.851 & 0.093 & 0.012 & 0.001 \\
\hline \multicolumn{9}{|l|}{ Sex } \\
\hline Male & $88(55.0)$ & $\begin{array}{l}1.14 \pm \\
0.80\end{array}$ & $1.58 \pm 0.91$ & $0.86 \pm 0.90$ & $0.77 \pm 0.78$ & $1.41 \pm 0.96$ & $1.26 \pm 0.98$ & $0.96 \pm 0.92$ \\
\hline Female & $72(45.0)$ & $\begin{array}{l}1.26 \pm \\
0.72\end{array}$ & $1.82 \pm 0.92$ & $0.86 \pm 0.80$ & $0.92 \pm 0.78$ & $1.54 \pm 1.04$ & $1.32 \pm 1.01$ & $1.10 \pm 0.89$ \\
\hline$p$-value & & 0.318 & 0.105 & 0.961 & 0.213 & 0.405 & 0.705 & 0.336 \\
\hline \multicolumn{9}{|l|}{ Relationship } \\
\hline Spouse & 71(44.4) & $\begin{array}{l}1.24 \pm \\
0.80\end{array}$ & $1.64 \pm 0.87$ & $0.98 \pm 0.92$ & $0.83 \pm 0.81$ & $1.52 \pm 0.94$ & $1.39 \pm 0.98$ & $1.05 \pm 0.95$ \\
\hline Parent & 17(10.6) & $\begin{array}{l}1.14 \pm \\
0.76\end{array}$ & $1.52 \pm 1.10$ & $0.85 \pm 0.84$ & $0.70 \pm 0.77$ & $1.37 \pm 1.12$ & $1.33 \pm 1.15$ & $1.06 \pm 0.81$ \\
\hline Children & $40(25.0)$ & $\begin{array}{l}1.08 \pm \\
0.66\end{array}$ & $1.74 \pm 0.93$ & $0.59 \pm 0.64$ & $0.74 \pm 0.64$ & $1.33 \pm 0.95$ & $1.14 \pm 0.95$ & $0.93 \pm 0.90$ \\
\hline Sibling & $23(14.4)$ & $\begin{array}{l}1.38 \pm \\
0.74\end{array}$ & $1.91 \pm 0.88$ & $1.05 \pm 0.92$ & $1.14 \pm 0.77$ & $1.75 \pm 1.07$ & $1.22 \pm 1.00$ & $1.19 \pm 0.83$ \\
\hline Others & $9(5.6)$ & $\begin{array}{l}1.01 \pm \\
0.95\end{array}$ & $1.53 \pm 1.03$ & $0.68 \pm 0.83$ & $0.79 \pm 1.09$ & $1.19 \pm 1.24$ & $1.19 \pm 1.06$ & $0.70 \pm 0.99$ \\
\hline$p$-value & & 0.554 & 0.645 & 0.146 & 0.332 & 0.444 & 0.758 & 0.658 \\
\hline \multicolumn{9}{|l|}{ Education } \\
\hline High school & $60(37.5)$ & $\begin{array}{l}1.38 \pm \\
0.78\end{array}$ & $1.84 \pm 0.89$ & $1.08 \pm 0.89$ & $0.95 \pm 0.83$ & $1.67 \pm 0.99$ & $1.50 \pm 1.07$ & $1.27 \pm 0.91$ \\
\hline College & $100(62.5)$ & $\begin{array}{l}1.09 \pm \\
0.73\end{array}$ & $1.61 \pm 0.92$ & $0.74 \pm 0.80$ & $0.78 \pm 0.75$ & $1.37 \pm 0.99$ & $1.17 \pm 0.92$ & $0.88 \pm 0.88$ \\
\hline$p$-value & & 0.019 & 0.132 & 0.016 & 0.170 & 0.066 & 0.050 & 0.010 \\
\hline \multicolumn{9}{|l|}{$\begin{array}{l}\text { Marital } \\
\text { status }\end{array}$} \\
\hline Single & $32(20.0)$ & $\begin{array}{l}1.01 \pm \\
0.73\end{array}$ & $1.59 \pm 0.92$ & $0.66 \pm 0.79$ & $0.70 \pm 0.72$ & $1.30 \pm 1.00$ & $1.13 \pm 0.98 a$ & $0.68 \pm 0.83 a$ \\
\hline Married & $122(76.3)$ & $\begin{array}{l}1.22 \pm \\
0.77\end{array}$ & $1.69 \pm 0.92$ & $0.91 \pm 0.87$ & $0.87 \pm 0.80$ & $1.49 \pm 1.01$ & $1.28 \pm 0.98 a$ & $1.06 \pm 0.90 a$ \\
\hline Separated* & $6(3.7)$ & $\begin{array}{l}1.71 \pm \\
0.49\end{array}$ & $2.15 \pm 0.86$ & $0.83 \pm 0.71$ & $0.96 \pm 0.88$ & $1.93 \pm 0.55$ & $2.33 \pm 0.78 b$ & $2.07 \pm 0.60 b$ \\
\hline$p$-value & & 0.120 & 0.456 & 0.315 & 0.544 & 0.367 & 0.039 & 0.003 \\
\hline \multicolumn{9}{|l|}{ Care } \\
\hline Yes & $84(52.5)$ & $\begin{array}{l}1.26 \pm \\
0.78\end{array}$ & $1.73 \pm 0.92$ & $0.85 \pm 0.84$ & $0.91 \pm 0.83$ & $1.62 \pm 0.98$ & $1.36 \pm 0.97$ & $1.11 \pm 0.97$ \\
\hline No & $76(47.5)$ & $\begin{array}{l}1.12 \pm \\
0.74\end{array}$ & $1.64 \pm 0.92$ & $0.87 \pm 0.87$ & $0.76 \pm 0.72$ & $1.31 \pm 1.00$ & $1.21 \pm 1.01$ & $0.92 \pm 0.83$ \\
\hline$p$-value & & 0.235 & 0.530 & 0.861 & 0.242 & 0.051 & 0.331 & 0.185 \\
\hline \multicolumn{9}{|l|}{ Employment } \\
\hline
\end{tabular}




\begin{tabular}{|llllllll|}
\hline Variable & $\mathrm{n}(\%)$ & Total & $\begin{array}{l}\text { Healthcare } \\
\text { staff }\end{array}$ & $\begin{array}{l}\text { Family / Social } \\
\text { support }\end{array}$ & $\begin{array}{l}\text { Practical } \\
\text { support }\end{array}$ & $\begin{array}{l}\text { Information and } \\
\text { education }\end{array}$ & $\begin{array}{l}\text { Psychological } \\
\text { problem }\end{array}$ \\
\hline Employed & $111(69.4)$ & $\begin{array}{l}1.24 \pm \\
0.78\end{array}$ & $1.71 \pm 0.89$ & $0.95 \pm 0.90$ & $0.89 \pm 0.81$ & $1.48 \pm 0.99$ & $1.33 \pm 1.01$ \\
support
\end{tabular}

Needs by psychosocial status and quality of life

In the caregivers of breast cancer survivors, a higher level of stress was correlated with higher unmet needs in all domains, and the group with the experience of despair for two or more weeks in a row showed higher unmet needs in all other domains than the 'healthcare staff' domain. In addition, the group with thoughts of suicide was found to have higher unmet needs in the domains of healthcare staff, practical support and religious support (Table 4). Caregivers with poorer QoL as assessed by EQ-5D showed higher levels of unmet needs $(1.50 \pm 0.70$ vs.1.03 \pm 0.74$)$ and their unmet needs were statistically significantly higher in all domains (Fig. 1, Supplementary table 3).

Table 4

Needs by psychosocial status of participants

\begin{tabular}{|c|c|c|c|c|c|c|c|c|}
\hline Variable & $n(\%)$ & Total & $\begin{array}{l}\text { Healthcare } \\
\text { staff }\end{array}$ & $\begin{array}{l}\text { Family / Social } \\
\text { support }\end{array}$ & $\begin{array}{l}\text { Practical } \\
\text { support }\end{array}$ & $\begin{array}{l}\text { Information and } \\
\text { education }\end{array}$ & $\begin{array}{l}\text { Psychological } \\
\text { problem }\end{array}$ & $\begin{array}{l}\text { Religious } \\
\text { support }\end{array}$ \\
\hline \multicolumn{9}{|l|}{ Stress } \\
\hline High & $40(25.3)$ & $\begin{array}{l}1.55 \pm \\
0.77 a\end{array}$ & $\begin{array}{l}2.04 \pm \\
0.74 a\end{array}$ & $1.19 \pm 0.90 a$ & $1.16 \pm 0.85 a$ & $1.72 \pm 0.94 a$ & $1.80 \pm 1.03 a$ & $1.36 \pm 1.00 \mathrm{a}$ \\
\hline A little & $90(57.0)$ & $\begin{array}{l}1.17 \pm \\
0.72 \mathrm{a}\end{array}$ & $\begin{array}{l}1.70 \pm \\
0.91 \mathrm{a}\end{array}$ & $0.80 \pm 0.80 b$ & $0.80 \pm 0.74 b$ & $1.55 \pm 0.98 a$ & $1.21 \pm 0.89 b$ & $0.94 \pm 0.87 b$ \\
\hline little & $28(17.7)$ & $\begin{array}{l}0.85 \pm \\
0.67 \mathrm{~b}\end{array}$ & $\begin{array}{l}1.25 \pm \\
0.93 b\end{array}$ & $0.63 \pm 0.85 b$ & $0.56 \pm 0.66 b$ & $0.94 \pm 0.96 b$ & $0.87 \pm 0.97 b$ & $0.85 \pm 0.79 b$ \\
\hline$p$-value & & 0.001 & 0.002 & 0.013 & 0.004 & 0.004 & $<0.001$ & 0.026 \\
\hline \multicolumn{9}{|c|}{$\begin{array}{l}\text { Despair ( } \geq 2 \\
\text { weeks) }\end{array}$} \\
\hline Yes & $20(12.7)$ & $\begin{array}{l}1.68 \pm \\
0.87\end{array}$ & $2.02 \pm 0.82$ & $1.31 \pm 0.95$ & $1.35 \pm 0.98$ & $1.92 \pm 1.00$ & $1.82 \pm 1.14$ & $1.68 \pm 1.01$ \\
\hline No & 137(87.3) & $\begin{array}{l}1.13 \pm \\
0.72\end{array}$ & $1.66 \pm 0.91$ & $0.80 \pm 0.82$ & $0.77 \pm 0.72$ & $1.41 \pm 0.98$ & $1.21 \pm 0.94$ & $0.94 \pm 0.86$ \\
\hline$p$-value & & 0.002 & 0.095 & 0.012 & 0.018 & 0.034 & 0.033 & $<0.001$ \\
\hline \multicolumn{9}{|c|}{$\begin{array}{l}\text { Thought of } \\
\text { suicide }\end{array}$} \\
\hline Yes & $13(8.3)$ & $\begin{array}{l}1.64 \pm \\
0.65\end{array}$ & $2.08 \pm 0.57$ & $1.24 \pm 0.76$ & $1.40 \pm 0.80$ & $1.85 \pm 0.74$ & $1.72 \pm 1.04$ & $1.56 \pm 0.79$ \\
\hline No & 144(91.7) & $\begin{array}{l}1.16 \pm \\
0.76\end{array}$ & $1.67 \pm 0.92$ & $0.83 \pm 0.86$ & $0.79 \pm 0.76$ & $1.44 \pm 1.01$ & $1.25 \pm 0.97$ & $0.98 \pm 0.91$ \\
\hline$p$-value & & 0.029 & 0.031 & 0.097 & 0.007 & 0.089 & 0.100 & 0.027 \\
\hline
\end{tabular}

Multiple regression analysis by needs

Multiple regression analysis was conducted to examine the effects of each independent variable on unmet needs by using the total score of each unmet need as the dependent variable, and the results are shown in Table 5. 
Table 5

The result of multiple regression analysis by needs

\begin{tabular}{|c|c|c|c|c|c|c|c|c|c|c|c|c|}
\hline \multirow[t]{2}{*}{ Variable } & \multicolumn{2}{|c|}{ Healthcare staff } & \multicolumn{2}{|c|}{$\begin{array}{l}\text { Family / } \\
\text { Social } \\
\text { support }\end{array}$} & \multicolumn{2}{|l|}{$\begin{array}{l}\text { Practical } \\
\text { support }\end{array}$} & \multicolumn{2}{|c|}{$\begin{array}{l}\text { Information } \\
\text { and } \\
\text { education }\end{array}$} & \multicolumn{2}{|c|}{$\begin{array}{l}\text { Psychological } \\
\text { problem }\end{array}$} & \multicolumn{2}{|c|}{ Religious suppc } \\
\hline & $\beta$ & $\mathrm{T}$ & $\beta$ & $\mathbf{T}$ & $\beta$ & $\mathbf{T}$ & $\beta$ & $\mathrm{T}$ & $\boldsymbol{\beta}$ & $\mathrm{T}$ & $\beta$ & $\mathbf{T}$ \\
\hline \multicolumn{13}{|l|}{$\begin{array}{l}\text { Age (ref: } \\
\leq 39 \text { ) }\end{array}$} \\
\hline $40-49$ & -0.001 & -0.006 & 0.232 & 1.113 & -0.089 & -0.450 & 0.114 & 0.451 & 0.145 & 0.618 & -0.065 & -0.3 \\
\hline $50-59$ & 0.226 & 0.898 & 0.507 & $2.249^{\star}$ & 0.054 & 0.253 & 0.461 & 1.683 & 0.389 & 1.532 & 0.321 & 1.41 \\
\hline$\geq 60$ & 0.236 & 0.846 & 0.653 & $2.612^{*}$ & -0.129 & -0.544 & 0.572 & 1.887 & 0.787 & $2.796^{\dagger}$ & 0.556 & $2.2 C$ \\
\hline \multicolumn{13}{|l|}{$\begin{array}{l}\text { Sex (ref: } \\
\text { Male) }\end{array}$} \\
\hline Female & 0.258 & 43887 & 0.227 & 1.521 & 0.236 & 1.665 & 0.151 & 0.834 & 0.111 & 0.658 & 0.288 & 1.91 \\
\hline \multicolumn{13}{|l|}{$\begin{array}{l}\text { Education } \\
\text { (ref: High } \\
\text { school) }\end{array}$} \\
\hline College & -0.105 & -0.574 & -0.225 & -1.367 & -0.212 & -1.356 & -0.065 & -0.327 & 0.031 & 0.169 & -0.120 & -0.7 \\
\hline \multicolumn{13}{|c|}{$\begin{array}{l}\text { Marital } \\
\text { status } \\
\text { (ref: Single) }\end{array}$} \\
\hline Married & -0.008 & -0.034 & -0.174 & -0.803 & 0.107 & 0.517 & -0.168 & -0.636 & -0.211 & -0.861 & 1.05 & $0.4 i$ \\
\hline $\begin{array}{l}\text { Separated } \\
\text { etc }\end{array}$ & 0.228 & 0.481 & -0.643 & -1.511 & -0.081 & -0.202 & 0.079 & 0.154 & 0.576 & 1.200 & 0.680 & $1.5 \varepsilon$ \\
\hline \multicolumn{13}{|c|}{$\begin{array}{l}\text { Employment } \\
\text { (ref: Yes) }\end{array}$} \\
\hline No & -0.125 & -0.660 & -0.503 & $-2.967^{\dagger}$ & -0.280 & -1.745 & -0.052 & -0.252 & -0.273 & -1.430 & -0.472 & -2.7 \\
\hline \multicolumn{13}{|c|}{$\begin{array}{l}\text { Religion (ref: } \\
\text { Yes) }\end{array}$} \\
\hline No & 0.280 & 1.826 & 0.029 & 0.211 & 0.008 & 0.062 & 0.217 & 1.298 & -0.073 & -473 & -0.276 & -1.9 \\
\hline \multicolumn{13}{|c|}{$\begin{array}{l}\text { Stress (ref : } \\
\text { Little) }\end{array}$} \\
\hline A little & 0.375 & 1.849 & 0.027 & 0.146 & 0.117 & 0.677 & 0.564 & $2.551^{*}$ & 0.206 & 1.005 & -0.092 & -0.5 \\
\hline High & 0.707 & $2.735^{\dagger}$ & 0.239 & 1.032 & 0.330 & 1.503 & 0.722 & $2.566^{*}$ & 0.700 & $2.681^{\dagger}$ & 0.164 & $0.6 \subseteq$ \\
\hline \multicolumn{13}{|c|}{$\begin{array}{l}\text { Despair (ref } \\
\text { : No) }\end{array}$} \\
\hline Yes & 0.151 & 0.615 & 0.314 & 1.425 & 0.367 & 1.755 & 0.370 & 1.384 & 0.361 & 1.453 & 0.508 & $2.2 \varepsilon$ \\
\hline \multicolumn{13}{|l|}{$\begin{array}{l}\text { Thought of } \\
\text { suicide } \\
\text { (ref : No) }\end{array}$} \\
\hline Yes & 0.707 & 0.243 & 0.034 & 0.131 & 0.262 & 1.065 & -0.019 & -0.061 & -0.160 & -0.549 & 0.035 & $0.1 £$ \\
\hline \multicolumn{13}{|l|}{$\begin{array}{l}\text { EQ5-D } \\
\text { (ref : No } \\
\text { problem) }\end{array}$} \\
\hline Problem & 0.205 & 1.196 & 0.284 & 1.842 & 0.202 & 1.384 & 0.147 & 0.787 & 0.271 & 1.563 & 0.203 & $1.3 c$ \\
\hline Adjusted & 0.074 & & 0.156 & & 0.095 & & 0.079 & & 0.185 & & 0.240 & \\
\hline F-value & 1.872 & & 3.008 & & 2.133 & & 1.931 & & 3.464 & & 4.433 & \\
\hline P-value & 0.034 & & $<0.001$ & & 0.013 & & 0.028 & & $<0.001$ & & $<0.001$ & \\
\hline
\end{tabular}


The age group of 60 years and older showed a higher level of unmet needs in family/social support, psychological problem and religious support. The employed group expressed greater needs for family/social support and religious support, and the religious group had higher needs for religious support than the irreligious group. The high stress group, i.e., the group of caregivers with higher levels of stress, showed a higher level of needs in the domains of family/social support, information and education and psychological problem. The group with the experience of despair showed higher unmet needs for religious support. Other differences in unmet needs according to sex, educational level and marital status were not statistically significant.

\section{Discussion}

The diagnosis of cancer has a long-term impact on the emotional, physical, social and spiritual aspects in all the family members as well as the patient. Caregivers play a very important role in offering optimal therapy to cancer survivors through preventing isolation, providing emotional support and managing physical impairment $[14,15]$.In this respect, an accurate assessment of unmet needs in cancer survivors and their caregivers is a very important step in the development of appropriate interventions to improve treatment effects, including QoL. Identification of the unmet needs of cancer survivors and caregivers will help healthcare staff to communicate with them easily and effectively, and thereby it will enable them to implement appropriate treatment-related decision making and provide improved treatment and care. So far, many studies have been conducted to identify unmet needs of cancer survivors and provide interventions to improve their QoL, but few attempts have been made to investigate unmet needs of caregivers. Therefore, we analyzed the unmet needs and QoL of caregivers of Korean breast cancer survivors through a multicenter cross-sectional interview survey.

Most caregivers start to perform their roles in a sudden situation even without having time to prepare. Therefore, they have various types and degrees of unmet needs, and they care for cancer survivors without their needs adequately satisfied in many cases. According to Heckel et al. [16], 57\% of cancer caregivers have at least one unmet need, and most commonly endorsed unmet needs are information and healthcare service needs. Recently, a systemic review also reported that information needs were the most prevalent unmet needs of caregivers [5]. In addition, in a study of caregivers of early stage breast cancer patients, healthcare service and communication needs were the highest ranked needs [17]. In the present study of caregivers of Korean breast cancer survivors, unmet needs were highest in the domain of 'healthcare staff' and the item with the highest unmet needs was 'needed information about the current status of the patient's illness and its future courses.' Among the top 10 unmet needs, 9 items belonged to the 'healthcare staff' domain, and these results suggest that most caregivers want to speak candidly with their healthcare staff in easy-to-understand terms about the illness, treatment and future of cancer survivors they care for. Recently, caregivers can acquire and share a lot of information through online services such as internet search or social networking services, but the conventional method of meeting unmet needs through interviews with healthcare staff is considered an important factor even these days. Therefore, healthcare staff is required to make an effort to communicate effectively with caregivers by providing adequate and relevant information in an empathetic manner. In particular, in Korea, high unmet needs for healthcare staff and information can be partially attributed to the fact that a very short time of 10 minutes or less per patient is generally allocated for outpatient treatments during which one-on-one individual consultation and information can be provided in most medical institutions. On the other hand, whereas emotional and psychological needs have been reported to be high in cancer survivors [18, 19], caregivers were found to have high needs for healthcare staff and information. These results are considered to reflect the situation where caregivers generally give greater focus to communication and information acquisition that are helpful for taking care of survivors rather than their own well-being.

Several studies have reported different results about the relationship between age and unmet needs in caregivers [6].This inconsistency of study findings is thought to be mainly due to the diversity of studies in terms of the subject population, conceptualization of unmet needs and measurement methods. Considering that spouses of cancer survivors (44.4\%) constituted a large percentage of the participants of this study, we reviewed previous studies conducted on the spouses of patients as caregivers, and unmet needs were found to be higher in caregivers aged 60 and older [20]. Our study also revealed that as age increased, unmet needs became higher in the family/social support, psychological problems and religious support domains. Caregivers with the educational level of high school or lower were found to have higher unmet needs in family/social support, psychological problem and religious support than the group with the educational level of college or higher. This result is consistent with the study by Berardi R. et al [14], which reported that as educational level was higher, the level of unmet needs decreased. These results are thought to be related to the fact that people with higher education levels are likely to have more opportunities to fulfill unmet needs through various mass media.

The presence of the spouse allows individuals to seek psychological stability through information acquisition and exchanges of opinions, and thereby it leads to an increase in satisfaction with life. In the case of separated (divorce, separation or bereavement) people, greater unmet needs arise because they have to rely only on healthcare staff. This study also found that unmet needs for psychological problem and religious support were higher in the group of people without the spouse, and these results were consistent with previous studies. ${ }^{6}$ The employed caregivers expressed greater needs for family/social support and religious support than the unemployed group, and this result supports previous research which reported that currently working family members have higher unmet needs [21]. Employed people have less time to spend with the family and acquaintances due to a lack of personal time, which leads to the neglect of interpersonal relationships, and work-related stress may have negative effects on family/social relationships. The religious group showed higher unmet needs for religious support than the irreligious group, and this result seems to show that caregivers with religious faith rely more on religion to deal with difficult situations and have spiritual interests. Since caregivers with higher unmet needs for religious support have been reported to experience more work limitations [22], efforts to address religious support needs are required even for social and economic development.

Caregivers of cancer survivors have diverse problems, including worsened physical health and severe psychological distress [23, 24]. Furthermore, in a prior study, the levels of distress and anxiety were found to be higher in them than cancer survivors they care for [25], and these problems have been reported to increase the burden of caregivers and decrease their QoL $[14,26]$.The analysis results of this study indicated that unmet needs are higher in the group with the experience of stress and despair, and unmet needs are associated with poorer QoL. These results were consistent with findings of previous studies [27, 28]. Since this study is a cross-sectional study, it is not clear whether stress and despair preceded or followed unmet needs, but if psychological support for caregivers is provided from the early stage of cancer diagnosis, it is expected to greatly help to reduce distress and alleviate unmet needs. In addition, since 
this psychosocial support can prevent the progression from the experiences of stress and despair to thoughts of suicide, which have been found to be closely related to unmet needs, early diagnosis and active interventions regarding the mental health status of caregivers are essentially required.

The level of QoL in caregivers of cancer survivors depends on changes in the situations of both survivors and caregivers [29]. Earlier stages of cancer and positive responses to treatment were positively associated with the caregiver's QOL. On the other hand, loss of physical strength, excessively demanding caregiving roles, feelings of being burdened, and the impact of caregiving on caregivers' lives are known to be related to lower levels of QoL of caregivers [30, 31]. In addition, unmet needs of caregivers are closely related to poorer QoL [10,32]. Consistent with previous studies, the results of this study also showed that the group with problems in the domains of QoL had statistically significant higher unmet needs in all domains, and in particular, poorer QoL was most highly correlated in unmet needs in the psychological problem domain. Therefore, knowledge about caregivers' unmet needs is necessary in order to help caregivers attain good QoL and maintaining the QoL of caregivers is important to providing effective care.

Ultimately, in multiple regression analysis, caregivers with older age, employment, the presence of religion, and higher levels of stress and despair in daily life expressed higher unmet needs. Therefore, the application of active and accessible programs (e.g., use of online platform) which can relieve unmet needs and improve QoL of vulnerable breast cancer caregivers will be able to produce better treatment outcome.

The present study has several limitations. First, we did not analyze differences in caregivers' unmet needs according to clinicopathological characteristics of breast cancer survivors. Second, this study is a hospital-based study and the participants were recruited only from six medical centers, so a careful approach is needed in generalizing the findings to all caregivers of Korean breast cancer survivors. Third, since this study is a cross-sectional study, we could not accurately evaluate cause-effect relationships. Therefore, more longitudinal studies with a rigorous study design should be adopted. Finally, the caregivers were recruited by universal sampling, which led to sampling bias. However, despite the limitations mentioned above, this study identified specific unmet needs of caregivers of Korean breast cancer survivors and related factors and showed that their QoL can be improved through efforts to address their unmet needs.

The application of a variety of practical and effective support programs through a multidisciplinary approach for not only cancer survivors but also caregivers will improve the treatment outcomes of cancer survivors and further lay the foundation for providing comprehensive cancer care.

\section{Conclusions}

The most prevalent unmet need in caregivers of Korean breast cancer survivors was found in the 'healthcare staff' domain and their QoL was closely related to unmet needs. In particular, in caregivers, older age, employment, religiousness, and higher levels of stress and despair in daily life were associated with higher unmet needs. Therefore, healthcare staff needs to accurately identify breast cancer caregivers vulnerable in terms of unmet needs and try to develop and apply tailored intervention programs that can systematically assist them.

\section{Abbreviations}

QoL

quality of life; CNAT-C:Comprehensive Needs Assessment Tool for Cancer Caregivers; EQ-5D:EuroQol-5 Dimensions

\section{Declarations}

\section{Ethics approval and consent to participate}

The study was approved by the Institutional Review Board, Jeonbuk National University Hospital, Jeonju, Korea (approval number 2016-01-018-004). Written informed consent was obtained from all individual participants included in the study.

\section{Consent for publication}

Not applicable.

\section{Availability of data and materials}

The datasets generated and/or analyzed during the current study are not publicly available due owing to data privacy policy at our facility, but are available from the corresponding author on reasonable request.

\section{Competing interests}

Authors declare that they have no conflict of interest or relationship with the sponsor of this work.

\section{Funding}

The present study was supported by grants from the research fund of Korean Society of Surgical Oncology in 2015.

\section{Authors' contributions}

Conception and design: HJ Youn. Analysis and interpretation of data: HJ Youn and J Lee. Acquisition of data: SK Lee, WS Kim, SY Jung, ZS Kim, JH Lee and MH Lee. Critical revision of the manuscript: HJ Youn and JW Lee. All authors prepared, reviewed and gave critical input into each stage of the manuscript. All authors approved the final version of the manuscript. 


\section{Acknowledgments}

We thank the Korean Breast Cancer Survivorship Research Group for their academic contribution to this research, and the caregivers of the survey for their cooperation.

\section{References}

1. Global cancer statistics 2018

Bray F, Ferlay J, Soerjomataram I, Siegel RL, Torre LA, Jemal A. Global cancer statistics 2018.

2. GLOBOCAN estimates of. incidence and mortality worldwide for 36 cancers in 185 countries. CA Cancer J Clin.

3. 2018.;68:394-424.

4. National Cancer Information Center (NCIS). https://www.cancer.go.kr/. Accessed 21 March 2020.

5. Preferences for and experiences of family

Shin DW, Cho J, Roter DL, Kim SY, Sohn SK, Yoon MS, et al. Preferences for and experiences of family.

6 . involvement in cancer treatment decision-making: patient-caregiver dyads study. Psycho-Oncology.

7. 2013.;22:2624-31.

8. Treatment decision-making in cancer care

Hubbard G, Illingworth N, Rowa-Dewar N, Forbat L, Kearney N. Treatment decision-making in cancer care.

9. the role of the carer. J Clin Nurs. 2010;19:2023-31.

10. Unmet care needs of advanced cancer patients and their

Wang T, Molassiotis A, Chung BPM, Tan JY. Unmet care needs of advanced cancer patients and their.

11. informal caregivers. a systematic review. BMC Palliat Care. 2018;17:96.

12. The unmet needs of partners and

Lambert SD, Harrison JD, Smith E, Bonevski B, Carey M, Lawsin C, et al. The unmet needs of partners and.

13. caregivers of adults. diagnosed with cancer: a systematic review. BMJ Support Palliat Care. 2012;2:224-30.

14. results of a

Family caregiver burden

Grunfeld E, Coyle D, Whelan T, Clinch J, Reyno L, Earle CC, et al. Family caregiver burden: results of a.

15. longitudinal study of. breast cancer patients and their principal caregivers. CMAJ. 2004;170:1795-801.

16. couples' and

Life after cancer

Hodgkinson K, Butow P, Hunt GE, Wyse R, Hobbs KM, Wain G. Life after cancer: couples' and.

17. partners' psychological adjustment and supportive care needs. Support Care Cancer. 2007;15:405-15.

18. Psychosocial care for family caregivers of patients

Northouse L, Williams AL, Given B, McCorkle R. Psychosocial care for family caregivers of patients.

19. with cancer. J Clin Oncol. 2012;30:1227-34.

20. Caregiver unmet needs

Hwang SS, Chang VT, Alejandro Y, Osenenko P, Davis C, Cogswell J, et al. Caregiver unmet needs, burden.

21. and satisfaction in symptomatic advanced cancer patients at a Veterans Affairs (VA) medical center. Palliat.

22. 1

319

29

Support C. $2003 ; 1: 319-29$.

23. The development of a comprehensive needs

Shin DW, Park JH, Shim EJ, Park JH, Choi JY, Kim SG, et al. The development of a comprehensive needs.

24. assessment tool for. cancer-caregivers in patient-caregiver dyads. Psycho-Oncology. 2011;20:1342-52.

25. Cross-cultural adaptation and validation of the Korean

Kim MH, Cho YS, Uhm WS, Kim S, Bae SC. Cross-cultural adaptation and validation of the Korean.

26. version of the EQ-5D in patients with rheumatic diseases. Qual Life Res. 2005;14:1401-6.

27. Pickard AS, Wilke CT, Lin HW, Lloyd A. Health utilities using the EQ-5D in studies of cancer.

28. Pharmacoeconomics. 2007;25:365-84.

29. Patient and caregiver needs

Berardi R, Ballatore Z, Bacelli W, Silva RR, Menichetti ET, Marcellini M, et al. Patient and caregiver needs.

30. in oncology. An Italian survey. Tumori. 2015;101:621-5.

31. Informal caregiving for cancer patients

Romito F, Goldzweig G, Cormio C, Hagedoorn M, Andersen BL. Informal caregiving for cancer patients.

Page $11 / 13$ 
32. Cancer. 2013;119:2160-9.

33. Unmet needs and depression

Heckel L, Fennell KM, Reynolds J, Osborne RH, Chirgwin J, Botti M, et al. Unmet needs and depression.

34. among carers of. people newly diagnosed with cancer. Eur J Cancer. 2015;51:2049-57.

35. Information needs and coping styles of

Nikoletti S, Kristjanson LJ, Tataryn D, McPhee I, Burt L. Information needs and coping styles of.

36. primary family caregivers. of women following breast cancer surgery. Oncol Nurs Forum. 2003;30:987-96.

37. intensity, and predictors of the supportive

Fiszer C, Dolbeault S, Sultan S, Brédart A. Prevalence. intensity, and predictors of the supportive.

38. care needs of. women diagnosed with breast cancer: a systematic review. Psycho-oncology. 2014;23:361-74.

39. Patients' supportive care needs

Armes J, Crowe M, Colbourne L, Morgan H, Murrells T, Oakley C, et al. Patients' supportive care needs.

40. beyond the end. of cancer treatment: a prospective, longitudinal survey. J Clin Oncol. 2009;27:6172-9.

41. Mason TM. Information needs of wives of men following prostatectomy. Oncol Nurs Forum. 2005;32:557-.

42. 63.

43. 21. Friðriksdóttir N, Saevarsdóttir T, Halfdánardóttir Sí, Jónsdóttir A, Magnúsdóttir H, Olafsdóttir KL, et al.

44. Family members of cancer patients: Needs, quality of life and symptoms of anxiety and depression. Acta Oncol.

45. 2011.;50:252-8.

46. 22. Park SM, Kim YJ, Kim S, Choi JS, Lim HY, Choi YS, et al. Impact of caregivers'unmet needs for

47. supportive care on quality of terminal cancer care delivered and caregiver's workforce performance. Support

48. Care Cancer. 2010;18:699-706.

49. 23. Stenberg U, Ruland CM, Miaskowski C. Review of the literature on the effects of caring for a patient with 50. cancer. Psycho-oncology. 2010;19:1013-25.

51. 24. Given B, Wyatt G, Given C, Sherwood P, Gift A, DeVoss D, et al. Burden and depression among caregivers 52. of patients with cancer at the end of life. Oncol Nurs Forum. 2004;31:1105-17.

53. 25. Sklenarova H, Krümpelmann A, Haun MW, Friederich HC, Huber J, Thomas M, et al. When do we need to

54. care about the caregiver? Supportive care needs, anxiety, and depression among informal caregivers of patients 55. with cancer and cancer survivors. Cancer. 2015;121:1513-9.

56. 26. Kim Y, Given BA. Quality of life of family caregivers of cancer survivors: across the trajectory of the illness. 57. Cancer. 2008;112:2556-68.

58. 27. Kim Y, Kashy DA, Spillers RL, Evans TV. Needs assessment of family caregivers of cancer survivors: three 59. cohorts comparison. Psycho-oncology. 2010;19:573 - 82.

60. 28. Printz C. Cancer caregivers still have many unmet needs. Cancer. 2011;117:1331.

61. 29. Kitrungroter L, Cohen MZ. Quality of life of family caregivers of patients with cancer: a literature review. 62. Oncol Nurs Forum.2006;33:625 - 32.

63. 30. Meyers JL, Gray LN. The relationships between family primary caregiver characteristics and satisfaction 64. with hospice care, quality of life, and burden. Oncol Nurs Forum. 2001;28:73-82.

65. 31. Northouse LL, Mood D, Kershaw T, Schafenacker A, Mellon S, Walker J, et al. Quality of life of women 66. with recurrent breast cancer and their family members. J Clin Oncol. 2002;20:4050-64.

67. 32. Kim Y, Carver CS. Unmet needs of family cancer caregivers predict quality of life in long-term cancer 68. survivorship. J Cancer Surviv. 2019;13:749 - 58

\section{Figures}




\section{Figure 1}

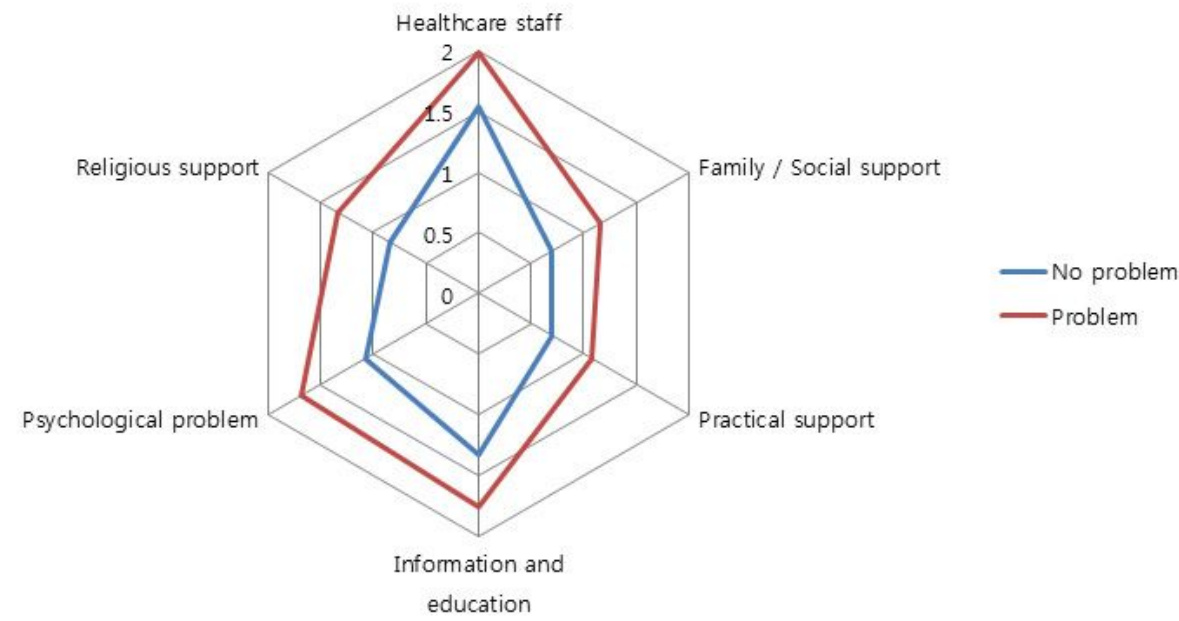

Figure 1

Needs by quality of life of study subjects

\section{Supplementary Files}

This is a list of supplementary files associated with this preprint. Click to download.

- supplement7.pdf

- supplement8.pdf

- supplement9.pdf

- supplement10.pdf

- supplement11.pdf

- supplement12.pdf

- supplement13.pdf

- supplement14.pdf

- supplement15.pdf

- supplement16.pdf

- supplement17.docx 